Article

\title{
Sexual violence experiences and pornography media exposure with sexual risk behavior among PLWHA MSM in Bandung Indonesia
}

\author{
Melly Rahmayani, ${ }^{1}$ Agung Waluyo, ${ }^{2}$ Riri Maria ${ }^{2}$ \\ ${ }^{1}$ Faculty of Nursing, Universitas Indonesia, Depok, West Java; ${ }^{2}$ Department of Medical surgical Nursing Faculty \\ of Nursing, Universitas Indonesia, Depok, West Java, Indonesia
}

\begin{abstract}
Background: HIV number continues to increase, especially among the minority of Men who have Sex with Men (MSM) due to the high risks of their sexual behavior. This study aims to identify the correlation between sexual violence experiences and pornography media exposure to sexual risk behavior among people with HIV/AIDS (PLWHA) MSM.

Design and Method: The study employed a cross-sectional design with the consecutive sampling technique and involved 258 PLWHA MSM under the guidance of an NGO in Bandung, Jawa Barat, Indonesia. The data were collected by employing an online questionnaire.

Result: The results show that there is a significant correlation between sexual violence experiences and sexual risk behavior $(\mathrm{p}$-value $=0.000, \alpha=0.05 ; \mathrm{OR}=6.496)$, pornography media exposure and sexual risk behavior ( $\mathrm{p}$-value $=0.000, \alpha=0.05$; OR $=4.271$ ). The multivariate analysis of multiple logistics regression results reveals that the sexual violence experience is the factor that mostly influences the sexual risk behavior among PLWHA MSM ( $\mathrm{p}$-value $=0.000, \alpha=0.05 ; \mathrm{OR}=3.784)$.

Conclusions: The sexual violence experiences and pornography media exposure have a significant positive relationship to sexual risk behavior. Therefore, nurses need to improve a comprehensive assessment, counseling, and personal education to reduce sexual risk behavior that can transmit HIV and other sexually transmitted diseases and create innovations through positive activities to reduce pornography consumption.
\end{abstract}

\section{Introduction}

HIV is a global issue, and the cases continuously increase every year. UNAIDS revealed that in 2018, 36.9 million people worldwide have HIV and AIDS. Adults dominate people living with HIV/AIDS (PLWHA) by 35.1 million, and the various risk groups are homosexual, transgender, commercial sex workers, and drug users. ${ }^{1}$

Indonesia is one of the countries in the Asia Pacific region with 620,000 PLWHA, with the highest number of PLWHA being Men having Sex with Men (MSM) by 9,522 people. $^{2}$ One of the provinces in Indonesia with the highest number of PLWHA is West Java. This Province is in the top three regions in Indonesia, with the highest number of PLWHA by 37,205 people. The most HIV/AIDS patients in West Java (4.832 HIV/AIDS) are found in Bandung as the Province's capital. 1,116 PLWHA MSM dominates in Bandung. They are treated in several hospitals in Bandung city. ${ }^{3}$

The high number of HIV in MSM is caused by several factors, like sexual risk behavior. Based on the study, there is a correlation between sexual risk behavior and the increasing incidence rate of HIV. The sexual risk behavior of MSM include multi-partners as well as perform oral sex and anal sex without condoms. ${ }^{4}$

Condomless anal intercourse is a common choice for an MSM and his partners and the pornography media influence its style of having sexual intercourse with its intimate partners MSM is a community that employed pornography media. ${ }^{5-7}$ Furthermore, they watch and fantasize sexual intercourse through pictures in gay magazines and internet-based networks. ${ }^{8}$

Pornography has more negative impacts on MSM sexual styles. Besides, pornography media is one-factor influencing sexual violence because pornography media displays sexual sadism and sadomasochism that can be imitated by the audience. ${ }^{9}$ Consequently, there is a tendency toward sexual violence. Furthermore, MSMs admit that pornography media makes them more aroused, and thus, they are eager to have more sex as they see it. $5,6,8$

According to the statement, there is a correlation between sexual violence experiences and drug use among MSM and inconsistency in using condoms as a form of sexual risk behavior. ${ }^{10}$ Childhood sexual abuse and intimate partner violence impact sexual risk behavior and increase the risk HIV transmission. ${ }^{11-13}$

Indonesia is a country where most of its population is Moslem, and MSM are less accepted. Therefore, MSM in Indonesia is still a minority group. Sexual violence among MSM in Indonesia is rarely reported. However, this does not mean that sexual violence has never occurred among MSM. It is estimated that one in ten MSM has experienced sexual harassment in a public space in Indonesia.

Furthermore, Indonesia prohibits pornography, but in reality, Indonesia is the third-largest country of accessing pornography

Significance for public health

The increasing number of PLWHA MSM is a concern in the world. Coupled with the increase in sexual violence and the development of pornographic media among MSM are also factors causing risky sexual behavior. Research on sexual violence, pornographic media, and sexual risk behavior in MSM is very important to prevent HIV transmission. Increased knowledge of these two aspects will assist MSM in engaging safe sex behavior. 
sites globally. Moreover, Indonesia has the highest number of internet users, and $64.8 \%$ of Indonesia's entire population is pornography users. The Province with the most increased access to the internet is West Java, especially in Bandung, as the capital of the Province (16\%).

Based on the problem, sexual violence is related to pornography media exposure and sexual risk behavior on MSM because pornography media indirectly provides an example of how to have sexual intercourse. Therefore, a study to describe the association between sexual violence experiences and pornography media exposure and sexual risk behavior is indispensable. The purpose of this study is to investigate the correlation between sexual violence experiences and pornography media exposure to sexual risk behavior and to investigate the most related factors to sexual risk behavior among PLWHA MSM.

\section{Design and Method}

This study employed a cross-sectional design and a consecutive sampling method. The participants of this research were 258 PLWHA MSM participants under the guidance of NGO Female Plus Bandung. The participants with inclusion criteria included men who self-reported having anal intercourse with at least one regular partner in the past six months and 18-year-old or older persons. This study excluded transgender. The data were collected by employing an online questionnaire in Google Form from 15 to 21 March 2020.

\section{Measuring instrument}

Four instruments were used in this research:

\section{Demographic characteristic instrument (21 Questions)}

This questionnaires to measure characteristic demographic of participants.

\section{Sexual risk behavior (10 Questions)}

This instrument to measure sexual risk behavior designed by Semple et al. DG This measurement has been translated into Bahasa Indonesia. ${ }^{14}$ This questionnaire has gone through a validity and reliability test with a Cronbach's alpha value of 0.936 .

\section{Sexual violence experiences (3 Questions)}

This instrument to measure sexual violence experiences designed by Semple et al. DG This measurement has been translated into Bahasa Indonesia. ${ }^{14}$ This questionnaire has gone through a validity and reliability test with a Cronbach's alpha value of 0.774 .

\section{Pornography media exposure (22 Questions)}

This instrument to measure pornography media exposure designed by Træen et al. This measurement has been translated into Bahasa Indonesia. ${ }^{6}$ This questionnaire has gone through a validity and reliability test with a Cronbach's alpha value of 0.970 .

\section{Statistical Analysis}

The data analysis of this research was univariate, bivariate, and multivariate analysis. Bivariate analysis were carried out using the Chi Square tests, while logisitic regression was also performed in this study for mutivariate analysis. The data analysis was conducted using SPSS version 21.

\section{Ethics Considerations}

All participants provided verbal and written consent before completing the commencement of the questionnaire to keep absolute anonymity. The written permission was signed with a nickname in the online google form. Ethics approval was obtained from the Ethics Committee of the Faculty of Nursing, Universitas Indonesia, Depok, Indonesia (Reference No.30/UN2.F12.D/ ETHICS.FIK. 2020).

\section{Results}

\section{Demographic characteristics}

This study's demographic characteristics are about demographics, sexual violence experiences, pornography media exposure, and sexual risk behavior. The demographic factor reveals that $91.1 \%$ of the participants are $18-39$ years old, and $68.6 \%$ are gay. The data also indicate that $55.3 \%$ of the participants hold secondary education degrees and their occupations are employees and entrepreneurs. Furthermore, the participants mostly have a regular partner type, and the average of Condomless Sexual Intercourse (CSI) of the participants with men within the last 6 months is 15 times. In addition to demographic data, the univariate analysis shows that $43.41 \%$ of the participants have high sexual violence experiences, $51.16 \%$ of them have high pornography media exposure, and $84.9 \%$ of them have high-risk sexual behavior (Table 1)

\section{The correlation between sexual violence experiences and pornography media exposure with sexual risk behavior}

The analysis of bivariate data by employing chi-square reveals that the sexual violence experiences have a significant correlation to sexual risk behavior ( $\mathrm{p}$-value $=0.000, \alpha=0.05$; CI 95\%), and the pornography media exposure has a significant correlation to sexual risk behavior ( $\mathrm{p}$-value $=0.000, \alpha=0.05$; CI 95\%). Furthermore, the data reveal that participants with high sexual violence experiences are 6.496 times more likely to have high-risk sexual behavior than those with low sexual violence experiences. Meanwhile, participants with high pornography media exposure have 4.271 times more likely to have high-risk sexual behavior than those with low-risk sexual behavior. The results of bivariate data analysis are presented in Table 2.

The association between ages, education, occupation, partner type, and frequency of condomless sexual intercourse with sexual risk behavior

This study analyzed the correlation of age, education, occupation, partner type, and condomless sexual intercourse (CSI) with men within the last 6 months with sexual risk behaviors. The results (as shown in Table 2.) show that age, education, occupation, type of partner do not significantly associate with sexual risk behavior among PLWHA MSM. However, Table 3 presents that the frequency of condomless sexual intercourse (CSI) with men within the last 6 months significantly associates with sexual risk behavior ( $\mathrm{p}$-value $=0.000, \alpha=0.05$; CI 95\%).

\section{Sexual violence experiences as dominant factor influ- encing sexual risk behavior}

Table 3 shows that the most dominant factor influencing sexual 
Table 1. Demographic characteristics $(\mathrm{N}=258)$.

\begin{tabular}{|c|c|c|c|c|c|}
\hline Characteristics & $(\mathrm{N})$ & $(\%)$ & Characteristics & (N) & $(\%)$ \\
\hline $\begin{array}{l}\text { Age } \\
\qquad \begin{array}{l}18-39 \text { years old } \\
40-65 \text { years old }\end{array}\end{array}$ & $\begin{array}{c}235 \\
23\end{array}$ & $\begin{array}{c}91.1 \\
8.9\end{array}$ & $\begin{array}{l}\text { Partner type } \\
\text { Regular } \\
\text { Casual }\end{array}$ & $\begin{array}{c}120 \\
58\end{array}$ & $\begin{array}{l}46.51 \\
22.48\end{array}$ \\
\hline $\begin{array}{l}\text { Education } \\
\text { Primary } \\
\text { Secondary } \\
\text { High } \\
\end{array}$ & $\begin{array}{c}61 \\
143 \\
54 \\
\end{array}$ & $\begin{array}{c}23.65 \\
55.3 \\
20.93\end{array}$ & $\begin{array}{l}\text { Regular and casual } \\
\text { Sexual violence experiences } \\
\text { Low } \\
\text { High }\end{array}$ & $\begin{array}{l}80 \\
146 \\
112\end{array}$ & $\begin{array}{l}31.01 \\
56.59 \\
43.41 \\
\end{array}$ \\
\hline $\begin{array}{l}\text { Job } \\
\text { Not working } \\
\text { Student } \\
\text { Civil servant/private employee } \\
\text { Self employed }\end{array}$ & $\begin{array}{c}51 \\
12 \\
103 \\
92\end{array}$ & $\begin{array}{c}19.77 \\
4.65 \\
39.92 \\
35.66\end{array}$ & $\begin{array}{l}\text { Pornography media exposure } \\
\text { Low } \\
\text { High } \\
\text { Sexual risk behavior } \\
\text { Low }\end{array}$ & $\begin{array}{l}126 \\
132 \\
39\end{array}$ & $\begin{array}{l}48.84 \\
51.16 \\
15.1\end{array}$ \\
\hline $\begin{array}{l}\text { Sexual preferences } \\
\text { Gay } \\
\text { Bisexual }\end{array}$ & $\begin{array}{l}177 \\
81\end{array}$ & $\begin{array}{l}68.6 \\
31.4\end{array}$ & $\begin{array}{l}\text { High } \\
\text { Frequency CSI with men within last } 6 \text { months }\end{array}$ & $\begin{array}{c}219 \\
\text { (Mean) } \\
15\end{array}$ & $\begin{array}{c}84.9 \\
(\operatorname{Min}-\operatorname{Max}) \\
1-120\end{array}$ \\
\hline $\begin{array}{l}\text { Marital status } \\
\text { Unmarried } \\
\text { Widower/divorce } \\
\text { Married } \\
\end{array}$ & $\begin{array}{l}211 \\
20 \\
27\end{array}$ & $\begin{array}{c}81.78 \\
7.75 \\
10.47 \\
\end{array}$ & & & \\
\hline
\end{tabular}

Table 2. Bivariate data analysis results $(\mathrm{N}=258)$.

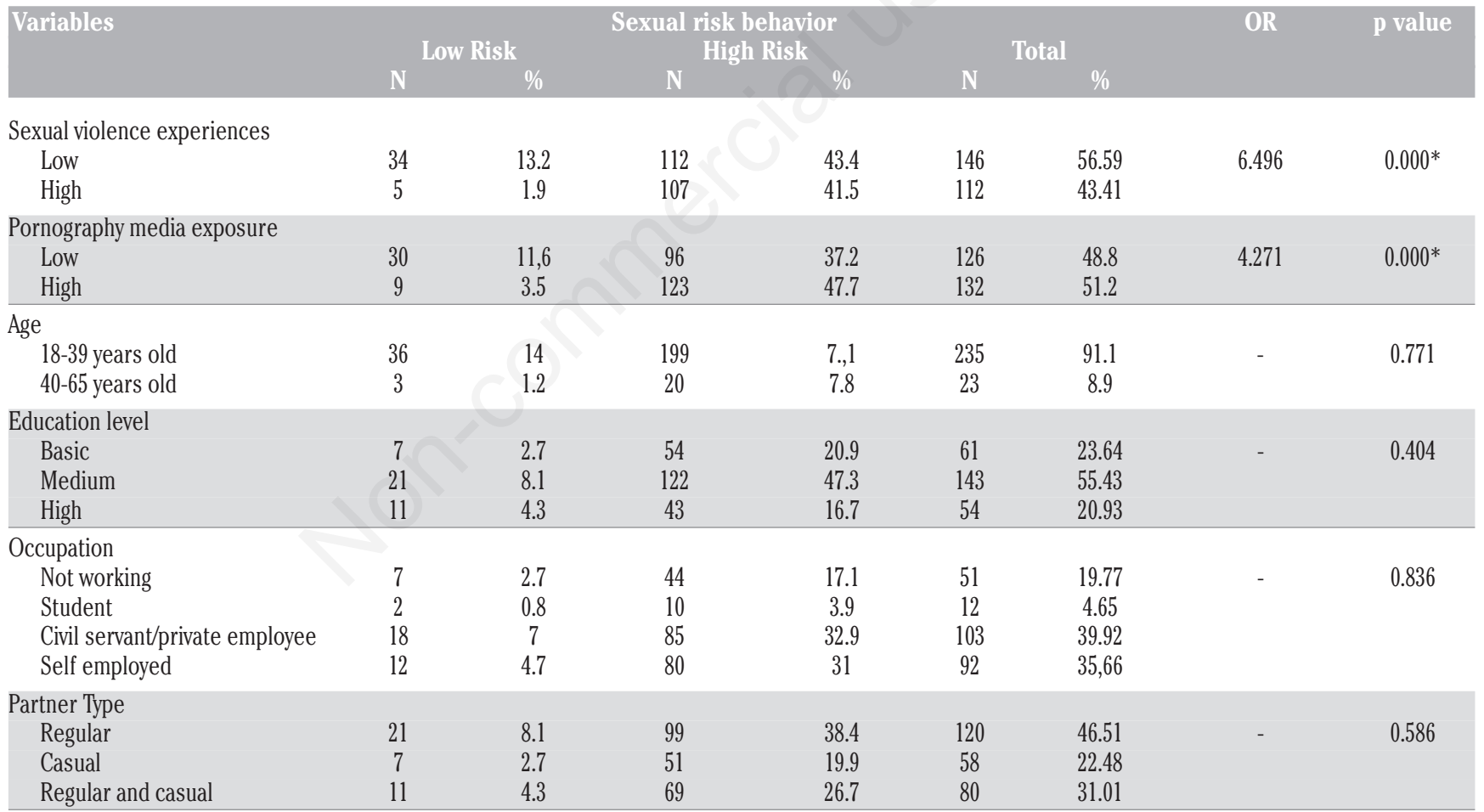

* Significant $\alpha=0.05$

Table 3. Multivariate data analysis results.

\begin{tabular}{lcccccc} 
Variabel & B & S.E & Wald & p value & OR & 95\%CI \\
Sexual violence experiences & 1,331 & 0,522 & 6,489 & 0,011 & 3,784 & $1,359-10,534$ \\
Pornography media exposure & 0,941 & 0,431 & 4,774 & 0,029 & 2,563 & $1,102-5,963$ \\
\hline Frecuency of CSI & 0,081 & 0,027 & 9,082 & 0,003 & 1,085 & $1,029-1,144$ \\
Constant & 0,193 & 0,297 & & & & \\
\hline
\end{tabular}


risk behavior is the sexual violence experiences with $\mathrm{OR}=3.784$ (CI 95\%: 1.359;1.534). The final multivariate result shows that the high-risk sexual behavior of the participants with high sexual violence experiences is 3.784 times higher than that of participants with low sexual violence experiences. Further statistical test results show that three variables, namely sexual violence experiences, pornography media exposure, and $92,7 \%$ of condomless sexual intercourse with men within last 6 months, can affect sexual risk behavior among PLWHA MSM.

\section{Discussion}

This study is the pilot project investigating the correlation between sexual violence experiences and pornography media exposure with sexual risk behavior among PLWHA MSM, which rarely reports sexual assault on MSM and prohibits pornography in Indonesia. The first findings identify that $84.9 \%$ of PLWHA MSM have high-risk sexual behavior. The second finding shows that $43.41 \%$ of PLWHA MSM have high sexual violence experiences. In contrast to this, in Mexico reveals that the proportion of experiencing high sexual violence is $25.3 \% .^{14}$

Statistically, sexual violence experiences have a significant association with sexual risk behavior. This finding is similar to that of Dunkle et al., ${ }^{15}$ who finds that MSM's sexual violence experiences can increase sexual risk behavior, especially anal sex without condoms. Meanwhile, in India, childhood sexual abuse potentially increases sexual risk behavior that can transmit HIV twice bigger. ${ }^{13}$ Different statement state that sexual behavior is at risk in MSM because the sexual violence experiences are less likely to occur. It occurs if immediate therapy is carried out or immediately after sexual violence occurs. ${ }^{16}$ Furthermore, it is affected by the type of sexual violence experienced, the duration of sexual violence occurred, the age of first experiencing sexual violence, the coping of individuals, mental health, and the involvement of alcohol or drugs.

According to Darmayanti \& Sumitri, ${ }^{17}$ sexual violence victims will feel negative impacts, such as stress, fear, shame, depression, and traumatics. However, in addition to these impacts, other effects are felt by MSM victims of sexual violence, such as the feeling of pleasure, addiction, desire to seek, and the desire to repeat to others. This suggests that sexual behavior in MSM is influenced by his sexual experiences, and this is in line with the theory that a person's behavior is derived from experience during the process of his or her life. MSM, who experienced sexual violence experiences, allows MSM to sexual violence with its sexual partners. MSM will commit violence or obtain sexual violence to get a different sensation from the sexual intercourse he has ever had, although it results in high-risk sexual behavior. ${ }^{18}$

These findings are similar to those of Stults et al. who state that MSM perpetrating sexual violence against their partners have experienced sexual violence as well by previous sexual partners. ${ }^{19}$ Their partner commits sexual violence while performing anal sex and oral sex without condoms, both as incertive and recertive. As a result, they tend to do the same to their current partner. It indicates that sexual violence experiences can directly influence MSM to commit sexual violence while conducting sexual behavior.

Third, sexual risk behavior is possibly influenced by pornography media exposure. Related to this, pornography media frequently feature anal sex and oral sex without condoms scenes, and MSM prefers pornography scenes. This finding is similar to that of Træen et al., ${ }^{6}$ who researches in Norway. This study reveals that $43.7 \%$ of MSMs prefer watching sex pornography scenes without condoms and pornography media exposure has a significant relationship with sexual risk behavior on MSM. According to Schrimshaw et $a l .{ }^{20}$ proportions are watching anal sex without condoms and condomless anal sex. However, if the balance of watching anal sex with condoms is high, condomless anal sex behavior will be low. Rosser et al. have a different opinion. ${ }^{21}$ They argue that overall pornography media exposure is not related to sexual risk behavior. Still, the scenes of condomless anal sex pornography have a direct relationship with condomless anal sex behavior.

The correlation between pornography media exposure and sexual risk behavior among PLWHA MSM arises from MSM and is influenced by the type of partner. This finding is similar to that of $\mathrm{Xu}$, Zheng, \& Rahman who state that the proportion watching pornography has a significant association to sexual risk behavior among MSM and depends on the type of partner who more possibly performs sexual risk behavior to their principal or regular partner. ${ }^{22}$ Pornography media exposure has a significant relationship to sexual risk behavior. It perhaps is influenced by other factors, such as partners, length of viewing, and sex scenes or styles watched in pornography. If they frequently watch sex scenes that use a condom, the sex style may be imitated, reducing sexual risk behavior.

This study reveals that the age, education, occupation, and type of partner do not significantly correlate to sexual risk behavior. Still, the frequency of condomless sexual intercourse with men within last 6 months has a significant correlation with sexual risk behavior. However, $91.1 \%$ of the participants of the study are young adults (18-39 years old). The majority of the participants has a regular partner, occupation, and secondary education graduates, and they have high-risk sexual behavior.

Khawcharoenporn et al. assert that young adults of PLWHA MSM are more likely to perform sexual risk behaviors that occur due to low knowledge about HIV and young adults' sexually productive age. ${ }^{23}$ Meanwhile, Boyer et al. define young adults as individuals who have the principles of free sex and easily change their partners and argue that young adults MSM have sexual relations with regular and casual partners. ${ }^{24}$ Therefore, they have sexual relations with more people, even though the relations are rare in frequency.

As for the type of partner, the results of this study are similar to those of the research by Rocha et al. who assert that there is no significant relationship between the type of partner and high-risk sexual behavior in PLWHA MSM with a regular partner, casual partner, or a commercial partner equally. ${ }^{25}$ Meanwhile, Kramer et $a l$. argue different opinion stating that there is a significant relationship between the type of partner and sexual risk behavior, especially condomless anal sex with the type of partner, and the results of the bivariate analysis show high-risk sexual behavior struck with a regular partner. ${ }^{26}$ They also find that propose a different argument. The bivariate analysis of this research shows a significant relationship between education and sexual risk behavior, and the high-risk sexual behavior is more performed by PLWHA MSM with primary education level or not finishing high school.

The learning process occurs, which is a form of synergy between behavioral formation factors. Even though a person has a higher education and knowledge of good health, it does not ensure their good health behaviors, as the environment could more influence it. However, the behavior is influenced not only by education and knowledge but also by the environment and genetics because, in reality, PLWHA MSM holding a primary, secondary, or high education are at high risk of sexual behavior.

This study reveals that: i) the frequency of condomless sexual intercourse with men within last 6 months influences sexual risk behavior in PLWHA MSM, ii) the average condomless sexual 
intercourse with men of low-risk sexual behavior is 6 times, average condomless sexual intercourse with men of high-risk sexual behavior is 16 times. These findings agree with those of there is a significant relationship between the frequency of sexual intercourse and sexual risk behavior that is condomless anal sex. Sexual behavior is at high risk in PLWHA MSMs who have sex $>10$ times, compared to those who only once.

The number of partners influences the frequency of sexual intercourse because PLWHA MSMs have multi partners. MSM's multi partners and more frequent-anal sex and oral sex without condoms will increase sexual risk behaviors. This finding agrees with the result of a study by Bengtsson et al. ${ }^{27}$ who state that sexual intercourse associated with sexual risk behavior in MSM is the frequency or number of anal sex without condoms. The frequency of condomless anal intercourse has a significant relationship with sexual risk behavior. Meanwhile, the frequency of condomless anal intercourse is apparently influenced by the number of partners

Correspondence: Agung Waluyo, Department of Medical surgical Nursing Faculty of Nursing, Universitas Indonesia, Jalan Prof. Dr. Bahder Djohan, UI Depok Campus, West Java 16424, Indonesia. Tel. +62.21.78849120 - Fax +62.21.7864124.

E-mail: agungwss@ui.ac.id

Key words: Sexual violence; MSM; pornography; sexual risk behavior.

Contributions: All authors contributed equally. AW, RM supervised conceptualization and design the study, revising it critically for important intellectual content, final approval. MR: concept and design analysis and interpretation of data, drafting manuscript

Conflict of interest: The authors declare no conflict of interest, financial or otherwise.

Acknowledgments: The author would to thank all respondents and all parties who had helped the completion of this research. Our deepest gratitude was also expressed to the Direktorat Riset dan Pengembangan Universitas Indonesia for funding this research with PUTI Prosiding Universitas Indonesia 2020, with contract number NKB-3432/UN2.RST/HKP.05.00/2020.

Institutions where the research was carried out: The research was carried out at Female Plus Bandung NGO at Bandung, West Java, Indonesia

Ethics approval and consent to participate: This study has been approved by the Ethics Committee of the Faculty of Nursing, Universitas Indonesia, Depok, Indonesia (Reference No.30/UN2.F12.D/ ETHICS.FIK. 2020).

Availability of data and materials: The data and materials regarding manuscript is readily available on request from corresponding author.

Conference presentation: This final manuscript has been presented at $7^{\text {th }}$ Virtual Biennial International Nursing Conference, Faculty of Nursing, Universitas Indonesia on September $24^{\text {th }}$, October $30^{\text {th }}$, November $16^{\text {th }} 2020$.

Received for publication: 10 August 2020.

Accepted for publication: 22 March 2021.

oCopyright: the Author(s), 2021

Licensee PAGEPress, Italy

Journal of Public Health Research 2021; 10(s1):2338

doi:10.4081/jphr.2021.2338

This work is licensed under a Creative Commons Attribution NonCommercial 4.0 License (CC BY-NC 4.0).
MSM since the frequency of condomless sexual intercourse is calculated by the number of couples and times they do with each partner. Sexual violence experiences, pornography media exposure, and frequency of sexual intercourse significantly correlate to sexual risk behavior in PLWHA MSM, and the most dominant factor influencing sexual risk behavior in PLWHA MSM is the sexual violence experiences. Nurses need to improve nursing care for PLWHA MSM through a comprehensive assessment to obtain information about sexual violence and pornography media exposure as an initial step to enhance nursing interventions, especially counseling and education, through more innovative approaches that will help reduce sexual behaviors at risks of transmitting HIV among PLWHA MSM.

The limitations of this study are: the questionnaires used have not described all types of sexual violence and sexual violence experiences studied have not been categorized based on the time of violent incidents (childhood, adolescents, and adults), and pornography media exposure is still analyzed in general perspectives.

\section{References}

1. UNAIDS. Global HIV \& AIDS statisticts-fact sheet. 2019. Available from: https://www.unaids.org /en/resources/factsheet

2. Ministry of Health of the Republic of Indonesia. [infoDATIN: Situasi umum HIVAIDS dan tes HIV berdasarkan laporan SIHA tahun 2013-2017 (infoDATIN: General situation of HIVAIDS and HIV testing based on the 2013-2017 SIHA report)].[in Indonesian]. Jakarta: Ministry of Health of the Republic of Indonesia; 2018. Available from: https://pusdatin.kemkes.go.id/resources/download/pusdatin/in fodatin/InfoDatin-HIV-AIDS-01.pdf

3. AIDS Prevention Commission. [Estimasi jumlah populasi kunci HIV di Indonesia 2016 (Estimates of the number of key HIV population in Indonesia 2016 t)].[in Indonesian].Bandung: AIDS Prevention Commission; 2017. Available from: https://kpakotabandung.or.id/book/estimasijumlah-populasi-kunci-hiv-di-indonesia-2016/

4. Hernandez I, Reina-Ortiz M, Johnson A, et al. Risk factors associated with HIV among men who have sex with men (MSM) in Ecuador. Am J Mens Health 2016;11:1331-41.

5. Nelson KM, Eaton LA, Gamarel KE. Preferences for condomless sex in sexually explicit media among Black/ African American men who have sex with men: implications for HIV prevention. Arch Sex Behav 2017;46:977-85.

6. Træen B, Noor SW, Hald GM, et al. Examining the relationship between use of sexually explicit media and sexual risk behavior in a sample of men who have sex with men in Norway. Scand J Psychol 2015;56:290-6.

7. Nelson KM, Leickly E, Yang JP, et al. The influence of sexually explicit online media on sex: do men who have sex with men believe they "do what they see"? AIDS Care 2014;26:931-4.

8. Downing Jr MJ, Schrimshaw EW, Scheinmann R, et al. Sexually explicit media use by sexual identity: a comparative analysis of gay, bisexual, and heterosexual men in the United States. Arch Sex Behav 2017;46:1763-76.

9. Centers for Disease Control and Prevention [Internet]. Sexual violence is preventable. Atlanta: CDC; 2019. Available from: https://www.cdc.gov/injury/features/sexualviolence/index.html

10. Chakrapani V, Lakshmi PVM, Tsai AC, et al. The syndemic of violence victimisation, drug use, frequent alcohol use, and 
HIV transmission risk behaviour among men who have sex with men: cross-sectional, population-based study in India. SSM - Population Health 2019;7:100348.

11. Brown TNT, Herman J. Intimate partner violence and sexual abuse among LGBT people. UCLA: The Williams Institute;. 2015 . Available from https://escholarship.org/uc/item/1qs269pk

12. Davis KC, Neilson EC, Wegner R, et al. The intersection of men's sexual violence perpetration and sexual risk behavior: a literature review. Aggress Violent Behav 2018;40:83-90.

13. Tomori C, McFall AM, Srikrishnan AK, et al. The prevalence and impact of childhood sexual abuse on HIV-risk behaviors among men who have sex with men (MSM) in India. BMC Public Health 2016;16:784.

14. Semple SJ, Stockman JK, Goodman-Meza D, et al. Correlates of sexual violence among men who have sex with men in Tijuana, Mexico. Arch Sex Behav 2017;46:1011-23.

15. Dunkle KL, Wong FY, Nehl EJ, et al. Male-on-male intimate partner violence and sexual risk behaviors among money boys and other men who have sex with men in Shanghai, China. Sex Transm Dis 2013;40:362-5.

16. Boroughs MS, Valentine SE, Ironson GH, et al. Complexity of childhood sexual abuse: predictors of current post-traumatic stress disorder, mood disorders, substance use, and sexual risk behavior among adult men who have sex with men. Arch Sex Behav 2015;44:1891-902.

17. Darmayanti YD, Sumitri S. [Faktor penyebab perilaku lakilaki suka berhubungan seks dengan laki- laki (LSL) di Kota Bukittinggi tahun 2016 (Factors causing male behavior like having sex with men (MSM) in Bukittinggi City in 2016)].[Article in Indonesian]. Jurnal Endurance: Kajian Ilmiah Problema Kesehatan 2018;3:213-25.

18. Sidjabat FN, Setyawan H, Setyawan SA. [Lelaki seks lelaki: aktivitas seksual dan bagaimana mereka memulaiknya? (Male sex men: sexual activity and how do they get
started?)].[Article in Indonesian]. IKESMA 2017;12:131-42.

19. Stults CB, Javdani S, Greenbaum CA, et al. Intimate partner violence and sex among young men who have sex with men. J Adolesc Health 2016;58:215-22.

20. Schrimshaw EW, Antebi-Gruszka N, Downing Jr MJ. Viewing of internet-based sexually explicit media as a risk factor for condomless anal sex among men who have sex with men in four U.S. Cities. PLoS One 2016;11:e0154439.

21. Rosser BRS, Smolenski DJ, Erickson D, et al. The effects of gay sexually explicit media on the HIV risk behavior of men who have sex with men. AIDS Behav 2013;17:1488-98.

22. Xu Y, Zheng Y, Rahman Q. The relationship between selfreported sexually explicit media consumption and sexual risk behaviors among men who have sex with men in China. J Sex Med 2017;14:357-65.

23. Khawcharoenporn T, Mongkolkaewsub S, Naijitra C, et al. HIV risk, risk perception and uptake of HIV testing and counseling among youth men who have sex with men attending a gay sauna. AIDS Res Ther 2019;16:13.

24. Boyer CB, Greenberg L, Korelitz J, et al. Sexual partner characteristics, relationship type, and HIV risk among a community venue-based sample of urban adolescent and young adult men who have sex with men. Youth Soc 2019;51:219-46.

25. Rocha GM, Kerr LRFS, Kendall C, et al. Risk behavior score: a practical approach for assessing risk among men who have sex with men in Brazil. Braz J Infect Dis 2018;22:113-22.

26. Kramer SC, Drewes J, Kruspe M, et al. Factors associated with sexual risk behaviors with non-steady partners and lack of recent HIV testing among German men who have sex with men in steady relationships: results from a cross-sectional internet survey. BMC Public Health 2015;15:702.

27. Bengtsson L, Lu X, Liljeros F, et al. Strong propensity for HIV transmission among men who have sex with men in Vietnam: behavioural data and sexual network modelling. BMJ Open 2014;4:e003526. 